\title{
Effect of Music - Raga Malkauns \& Yaman on Emotional Intelligence and General Intelligence Among Undergraduate Medical Students
}

\section{IJCRR}

Section: Healthcare

ISI Impact Factor

(2019-20): 1.628

IC Value (2019): 90.81

SJIF (2020) $=7.893$

(c) (1) (3)

Copyright@IJCRR

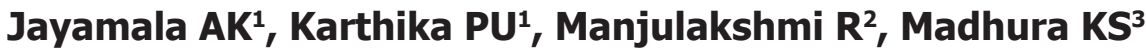

\begin{abstract}
'Department of Physiology, Sri Venkateshwara Medical College Hospital \& Research Centre, Pondicherry, India; ${ }^{2} 3$ rd-year MBBS, Department of Physiology, Sri Venkateshwara Medical College Hospital \& Research Centre, Pondicherry, India; ${ }^{3}$ Karnatic Music Junior-vocalist, Pondicherry, India.
\end{abstract}

\section{ABSTRACT}

Background: Medical education poses immense stress on undergraduate medical students due to workload \& competitive clinical training environment. A high level of stress has a negative effect on cognition. Music intervention is known to reduce stress, thereby improving cognition. High emotional intelligence subjects cope well with their own emotions as well as respond better to patients emotions thereby have a good patient-doctor relationship. With this background, the Effect of Raga Malkauns \& Yaman on general \& emotional intelligence is assessed in this study.

Materials and Methods: Thirty undergraduate medical students of both genders were recruited randomly based on inclusion \& exclusion criteria. Assessment of emotional intelligence \& general intelligence was done before and after music intervention. Pre-recorded music Raga Malkauns \& Yaman was heard by students for 6days /week for 6 weeks in the department of Physiology.

Results: After music intervention, significant improvement in general intelligence test - DSST (digit symbol substitution test) scores $(p=0.0005)$ but not in global emotional intelligence or any of the four subscales of EI $(p>0.41)$.

Conclusion: Listening to music helps in the improvement of GI thereby helps in improving academic performance. No improvement in El was noted.

Key Words: Cognition, Emotion, Stress, Young adults

\section{INTRODUCTION}

Daniel Goleman a distinguished psychologist defines Emotional Intelligence (EI) as "the capacity for recognising our feelings and those of others, for motivating ourselves, and for managing emotions well, in ourselves and our relationships". ${ }^{1}$.EI is an essential aspect of human interactions. People with high EI cope well with their own emotions, notice and respond appropriately to the emotions of other people. The medical profession thrives on human interactions. High EI level has been reported to contribute positively towards a healthy doctor-patient relationship, increased empathy, teamwork and communication skills, stress management, organisational commitment and leadership. ${ }^{2}$ Perceiving and managing emotions is fundamental to medicine as physicians must navigate their own emotions as well as the emotions of the patients and other team members, to succeed as effective practitioners.
Our medical training focuses mainly on cure, amelioration of disease, and the restoration of good health but it fails to teach, how to handle emotional situations, witness the dying process and communicate during the period of grief. In an era of competitiveness, students are forced to develop an attitude of passive knowledge acquisition and skill gathering sometimes even forgetting the patient, the very reason for his existence. Physicians are trained to strive for detachment to their professional competence to cure the disease rather than empathising with the patient. Improving observational skills (to detect patient emotions) and communication skills (to convey his feelings to the bereaved family) can help in sensitising the undergraduate students to be more empathising with patients. ${ }^{3}$

Though general Intelligence is essential for both short term and long term memory, attention, perception \& problemsolving in medical education, it poses considerable stress

\section{Corresponding Author:}

Dr. Jayamala A.K., Department of Physiology, Sri Venkateshwara Medical College Hospital \& Research Centre, Pondicherry- 605010, India. Email: drjayamala2013@gmail.com

ISSN: 2231-2196 (Print) ISSN: 0975-5241 (Online)

Received: $18.01 .2021 \quad$ Revised: 09.03 .2021

Accepted: 20.04 .2021

Published: 12.09 .2021 
on undergraduate students \&trainees due to the immense academic workload and competitive clinical training environment. ${ }^{4}$ High level of stress has a negative impact on the cognitive function and learning potential of the students. ${ }^{5}$

Music is an art of sound in time. The capacity of music to communicate emotions is one of the important functions of music. In Indian classical music, Ragas are the one that constitutes to specific combinations of tonic intervals that are capable of evoking distinct emotions. Music was also known to enhance cognition by relieving stress and by inducing a moderate level of arousal \& pleasant mood. Various studies have reported the association between Emotional Intelligence (EI) and academic performance. ${ }^{6,7}$ Though many studies have been done to find the effect of music on general and emotional intelligence, not any of the studies were done among medical students' emotional intelligence, hence this study was chosen.

\section{HYPOTHESIS}

Music has a positive impact on general and emotional intelligence among medical students.

\section{OBJECTIVES}

1) To determine the effect of Indian Raga Malkauns and Yaman on Emotional Intelligence

2) To determine the effect of Indian Raga Malkauns and Yaman on General Intelligence

3) To Correlate and compare the relation between Emotional Intelligence and General Intelligence

\section{METHODOLOGY}

\section{Sample size estimation:}

An institution-based interventional study was conducted in the department of Physiology after obtaining Institutional Ethics Committee clearance. Thirty volunteers from secondyear MBBS (sample size estimated was 22 using Open Epi software based on the mean and SD obtained from the previous study. ${ }^{8}$ Considering $20 \%$ nonresponsive rate and few loss to follow up rate the sample size included in the study is 30) aged between 18 and 25 years of both the sex were recruited randomly. Subjects with a history of epilepsy, diabetes, hearing impairment and those who were already acquainted with Indian classical music were excluded from the study. After explaining the purpose of the study, informed written consent was obtained from all the participants. Demographic data were collected. Emotional Intelligence (EI) and General Intelligence (GI) score was recorded before and after music intervention using a questionnaire.

\section{Emotional intelligence (ei):}

TEQ- SF is a validated questionnaire used to score TraitEmotional intelligence among undergraduate medical students. ${ }^{11}$ It is developed by K. V. Petrides, Director of the London Psychometric Laboratory at University College London (UCL). TEQ- SF includes 2 items from each of the 15 facets of the trait EI sampling domain which can be used in research designs with limited experimental time. TEIQue-SF yields scores on global trait EI and its four subscales (Wellbeing, Self-control, Emotionality, and Sociability). ${ }^{9}$

\section{General intelligence (gi):}

Tests to assess the executive aspect of cognition function was used to assess general intelligence as it is known to be independent of Mozart effect of music. ${ }^{10}$.

\section{Digit symbol substitution test (DSST):}

This test assesses the neuropsychological activity of the brain. The key consists of a list of one digit \&one symbol in pairs (e.g. 1/-, 9/=). The test items are printed below the key. Participants were instructed to draw the symbol below the appropriate digit by seeing the key. The first 10 items were used as practice items, to ensure that participants understand the test instructions. After completion of 10 practice items, participants are instructed to complete the test as fast as possible. Based on the number of correct substitutions made in 90 seconds, a score was awarded. ${ }^{11}$

\section{Letter digit substitution tests (LDST):}

In the LDST test, the key gives the numbers 1 to 9 , each paired with a different letter; the test items were printed below the key. Participants were instructed to replace the letters which are randomized with the appropriate digit by seeing the key. The first 10 items were used to practice, to ensure that participants understand the instructions. After completion of 10 practice items, participants were instructed to draw the remaining items as fast as possible. The number of correct substitutions made in 60 seconds is measured and a score was given.

\section{Music intervention:}

All 30 participants were instructed to listen to Indian classical Music Raga 'Malkauns' and Yaman for 30mins daily for 6 days a week for6 weeks from 5.00 to $6.00 \mathrm{pm}$ in the department of Physiology using pre-recorded Raga Malkauns and Yaman by flute with earphones at a comfortable level of volume of their choice from the android mobile phone. Raga Malkauns \& Yaman by Pandit Raghunath Seth was included based on trained musicians opinions. Raga Malkauns is known for its special appeal to human feelings. In Indian classical music, Malkauns belongs to the Bhairavi That. Malkauns is a meditative raga and is developed mostly in the lower octave \& in a slow tempo. Rabindra Sangeet based on 
raga Malkauns has a strong positive effect in relieving stress from human beings. ${ }^{12}$

\section{Statistical analysis:}

The data is analysed using SPSS version 23. All the values were expressed as Mean \pm SD. The student's paired "t" test was used to compare EI \& GI scores before and after music intervention. Pearson's correlation was used to determine the correlation between EI \& GI.

\section{RESULTS}

The mean age of male and female participants was $19.47 \pm 1.76 \mathrm{yrs}$ and $19.24 \pm 1.47 \mathrm{yrs}$ respectively. Emotional Intelligence (EI) and General Intelligence (GI) was scored before and after music intervention. Table 1 provides the effect of music on general intelligence. Digit symbol substitution test (DSST) test scores show significant improvement after music. Letter digit substitution tests (LDST) score did not show significant improvement after music. Table 2 shows that TEI global score and the four subscales proved to be independent of the music, $p>0.41$. Table 3 provides a correlation among five measures of EI (TEI global \& four subscale scores) and 2 IQ measures (DSST \& LDST). The global score of the TEI test did not show a correlation with any of the GI tests. TEI subscale- Self-control and Emotionality showed a strong significant positive association with the DSST \& LDST.

\section{DISCUSSION}

This study aimed to test the hypothesis that listening to music-Raga Malkauns \& Yaman is associated with improved emotional and general intelligence among undergraduate medical students. The key finding was that music had increased the executive aspect of cognition, but not the Global Emotional intelligence score or any of the four subscales of emotional intelligence.

Our results are similar to the study done by Schellenberg et al. were listening to music was positively associated with IQ in school children. Listening to Mozart music for 10mins was known to improve spatial reasoning skills. According to the Mozart effect, any cognitive enhancement did not last longer than $10-15 \mathrm{mins}$, and the increase in IQ is mainly because of 'enjoyment arousal'. It was also found that the Mozart effect does not influence the executive function of cognition. So to avoid the Mozart effect, in our study executive aspect of cognition was measured using LDST, DLST. ${ }^{10}$

Subdivision of executive functions such as planning, attention, inhibition and working memory plays a crucial role in the general intelligence process. In our study, we found a sig- nificant improvement in DSST score after 6weeks of listening to music. Similarly, Jaschke et al. showed that children following structured music lessons perform better on tasks measuring verbal IQ, planning \& inhibition subdivision of executive functions during two and half year follow-up with music interventions. ${ }^{13}$ Our findings were further supported by Karuna Nagarajan et al. where Indian Raga Bhupaliand was shown to have a significant effect on cognition. ${ }^{14}$ Also studies on Raga Darbari showed enhancement in cognitive performance as a direct consequence of listening to music among medical college students.

In child musicians, fMRI and neuropsychological testing showed increased brain activity in the Ventro-Lateral Prefrontal cortex (VL-PFC) and medial prefrontal cortex which are involved in executive sub-functions. Thus, these areas are equally recruited while playing music which might be the reason for increased cognition and academic performance ${ }^{15}$

Similar to our results, a study done on musically trained participants showed higher IQs but not EI when compared with untrained counterparts. ${ }^{16}$ In contrast, listening to Indian classical music Hamsadhvani had shown a significant effect on Emotional Intelligence among young adults.

According to our results in table 3, self-control and emotional stability were known to be positively correlated with an executive aspect of cognition. People with high Emotional intelligence (EI)was known to have lower perceived stress despite high Cortisol levels at baseline compared to subjects with low EI subjects. In contrast, GI showed no significant correlation with EI and stress level. ${ }^{17}$ Positive correlation between EI and academic performance is noted in many studies. ${ }^{6,7}$ Intelligence is said to be directly related to academic success and the higher the emotional intelligence, the higher will be the academic success and vice versa. It can be assumed that for better academic performance, students' emotional intelligence has to be enhanced. ${ }^{18}$

Continuous development of EI skills is assumed to help students cope with stressful environments. Raga Malkauns has a strong positive effect in relieving stress from human beings. It conveys a mood that is serene, calm, peaceful, joyful and lively. ${ }^{12}$ Thus listening to these types of ragas can relieve stress and improve the emotional intelligence and general intelligence in medical students.

Medical students with high EQ have the potential to become effective compassionate physicians who are in a position to communicate well with patients. A high level of EI is a protective factor in the occurrence of mental disorders, including depression, affects the treatment process in patients and also the creation of effective strategies for coping with stress. ${ }^{19}$ Surgeons EI have a positive effect on patient-rated patientsurgeon relationships. ${ }^{20}$ EI among clinical postgraduate students was positively associated with age but negatively cor- 
related with the workload, longer night duty hours, \& more sudden emergency duties. ${ }^{21}$ EI training programs for a surgical speciality, otolaryngology, showed that a faculty-led and mentored interactive training program using high-risk/highstress simulations enhanced participants' recognition, understanding, and management of emotions. When followed over some time, these changes were reflected in increased patient satisfaction with their physicians. ${ }^{22}$ EQ has growth potential and inherent plasticity. Hence EI must be addressed collaboratively by the students, faculty and administration to improve patient care in a tertiary care hospital.

\section{CONCLUSION}

Listening to Music helps in the improvement of general intelligence thereby helps in improving academic performance in medical undergraduates. No improvement in emotional intelligence was noted. At the same time, no deleterious effect of music was observed in emotional intelligence.

\section{LIMITATION}

In our study the duration of music listened was 6 weeks, a study on the long term effect of music on Emotional and general intelligence is required.

\section{Conflict of Interest: None}

\section{Source of Funding: None}

\section{ACKNOWLEDGEMENT}

Authors acknowledge the study participants for their time and commitment to follow the instructions given by the principal investigators. The authors acknowledge the immense help received from the management $\&$ dean of our institute for providing us with the required infrastructure to carry out this work even after working hours. We also thank the scholars whose articles are cited and included in references of this manuscript.

\section{REFERENCES}

1. Cherniss C, Extein M, Goleman D, Weissberg RP. Emotional intelligence: What does the research really indicate?. Educational Psychologist. 2006; 41(4): 239-245.

2. Azimi S, AsgharNejad Farid AA, Kharazi Fard MJ, Khoei N. Emotional intelligence of dental students and patient satisfaction. Eur. J. Dent. Educ. 2010;14(3):129-132.

3. Mishra S. Do we need to change the medical curriculum: regarding the pain of others. Indian Heart J. 2015; 67(3):187.

4. Dyrbye LN, Harper W, Moutier C, Durning SJ, Power D V, et al. A Multi-institutional study exploring the impact of positive mental health on medical students' professionalism in an era of high burnout. Acad Med. 2012;87(8):1024-1031.

5. Abdulghani HM, AlKanhal AA, Mahmoud ES, Ponnamperuma GG, Alfaris EA. Stress and its effects on medical students: A cross-sectional study at a college of medicine in Saudi Arabia. J Heal Popul Nutr. 2011;29(5):516-522.

6. Ranasinghe P, Wathurapatha WS, Mathangasinghe Y, Ponnamperuma G. Emotional intelligence, perceived stress and academic performance of Sri Lankan medical undergraduates. BMC Med Educ. 2017;17(1):41

7. Wijekoon CN, Amaratunge H, De Silva Y, Senanayake S, Jayawardane P, Senarath U. Emotional intelligence and academic performance of medical undergraduates: A cross-sectional study in a selected university in Sri Lanka. BMC Med Educ. 2017; 17(1):1-11.

8. Vijayabanu U, Menon R. Impact of music intervention on emotional intelligence. Int J Humanit Arts Med Sci . 2016;4(1):1924.

9. Cooper A, Petrides K V. A psychometric analysis of the Trait Emotional Intelligence Questionnaire-Short Form (TEIQue-SF) using item response theory. J Pers Assess. 2010;92(5):449-457.

10. Franco F, Swaine JS, Israni S, Zaborowska KA, Kaloko F, et al. Affect-matching music improves cognitive performance in adults and young children for both positive and negative emotions. Psychol Music. 2014;42(6):869-887.

11. Jaeger J. Digit symbol substitution test. J Clin Psychopharmacol. 2018;38(5):513-519.

12. Mukherjee S, Palit SK, Banerjee S, Bhattacharya DK. A comparative study on three different types of music based on the same Indian raga and their effects on human autonomic nervous systems. In: Springer Proceedings in Complexity. Springer; 2015; 243-254.

13. Jaschke AC, Honing H, Scherder EJA. Longitudinal Analysis of Music Education on Executive Functions in Primary School Children. Front Neurosci. 2018;12:103.

14. Nagarajan K, Srinivasan T, Ramarao N. Immediate effect of listening to Indian raga on attention and concentration in healthy college students: A comparative study. J Heal Res Rev. 2015;2(3):103-107.

15. Zuk J, Benjamin C, Kenyon A, Gaab N. Behavioral and Neural Correlates of Executive Functioning in Musicians and Non-Musicians. PLoS One. 2014;13(1): e0191394.

16. Schellenberg EG. Music lessons, emotional intelligence, and IQ. Music Percept. 2011;29(2):185-194.

17. Singh Y, Sharma R. Relationship between general intelligence, emotional intelligence, stress levels and stress reactivity. Ann Neurosci. 2012;19(3):107-111.

18. Id QS, Hussain I, Syed MA, Parveen R, Lodhi S, Mahmood Z. Association between emotional intelligence and academic success among undergraduates : A cross-sectional study in. PLoS One. 2019;1-22.

19. Żuchowicz P, Skiba A, Gałecki P, Talarowska M. The emotional intelligence in major depressive disorders. Pol Merkur Lekarski. 2018;45(267):131-133.

20. Weng HC, Steed JF, Yu SW, Liu Y Ten, Hsu CC, Yu TJ, et al. The effect of surgeon empathy and emotional intelligence on patient satisfaction. Adv Heal Sci Educ. 2011 Dec ;16(5):591-600.

21. Ravikumar R, Rajoura OP, Sharma R, Bhatia MS. A Study of Emotional Intelligence Among Postgraduate Medical Students in Delhi. Cureus. 2017;9(1):1-10.

22. Dugan JW, Weatherly RA, Girod DA, Barber CE, Tsue TT. A longitudinal study of emotional intelligence training for otolaryngology residents and faculty. JAMA Otolaryngol - Head Neck Surg. 2014;140(8):720-726. 
Table 1: Effect of music on general intelligence

\begin{tabular}{lcccc} 
N=29 & $\begin{array}{c}\text { Before music } \\
(\text { mean } \pm \text { SD })\end{array}$ & After music $($ mean \pm SD $)$ & Q - value & p-value \\
DSST & $44.24 \pm 7.67$ & $48.12 \pm 6.41$ & 4.513 & $0.0005^{*}$ \\
LDST & $45.92 \pm 5.32$ & $46.64 \pm 7.28$ & 0.7707 & 0.130 \\
\hline
\end{tabular}

Digit symbol substitution test (DSST), Letter digit substitution tests (LDST)

Table 2: Effect of music on emotional intelligence

\begin{tabular}{lccc} 
N=29 & Before music $($ mean \pm SD) & After music $($ mean \pm SD) & P value \\
TEI (WB) & $4.58 \pm 0.92$ & $4.56 \pm 0.95$ & 0.933 \\
TEI(SC) & $4.17 \pm 0.77$ & $4.06 \pm 0.89$ & 0.417 \\
TEI (E) & $4.32 \pm 0.86$ & $4.36 \pm 0.87$ & 0.843 \\
TEI(S) & $4.15 \pm 0.73$ & $4.16 \pm 0.74$ & 0.946 \\
TEI(global) & $4.30 \pm 0.58$ & $4.30 \pm 0.65$ & 0.978 \\
\hline
\end{tabular}

TEI- Trait Emotional Intelligence, (WB: Well-being, SC: Self-control, E: Emotionality, and S: Sociability)

Table 3: Correlation between General Intelligence and Emotional Intelligence

\begin{tabular}{lccccc} 
& EI (global) & TEI (WB) & TEI(SC) & TEI (E) & TEI(S) \\
DSST & 0.17 & 0.218 & $0.008^{* *}$ & 0.065 & -0.374 \\
LDST & 0.209 & 0.261 & 0.113 & $0.044^{*}$ & 0.067 \\
\hline
\end{tabular}

Digit symbol substitution test (DSST), Letter digit substitution tests (LDST), TEI- Trait Emotional Intelligence, (WB: Well-being, SC: Self-control, E: Emotionality, and S: Sociability)

$\mathrm{N}=29, \mathrm{p}<0.05^{*}, \mathrm{p}<0.01^{* *}, \mathrm{p}<0.001^{* * *}$ 